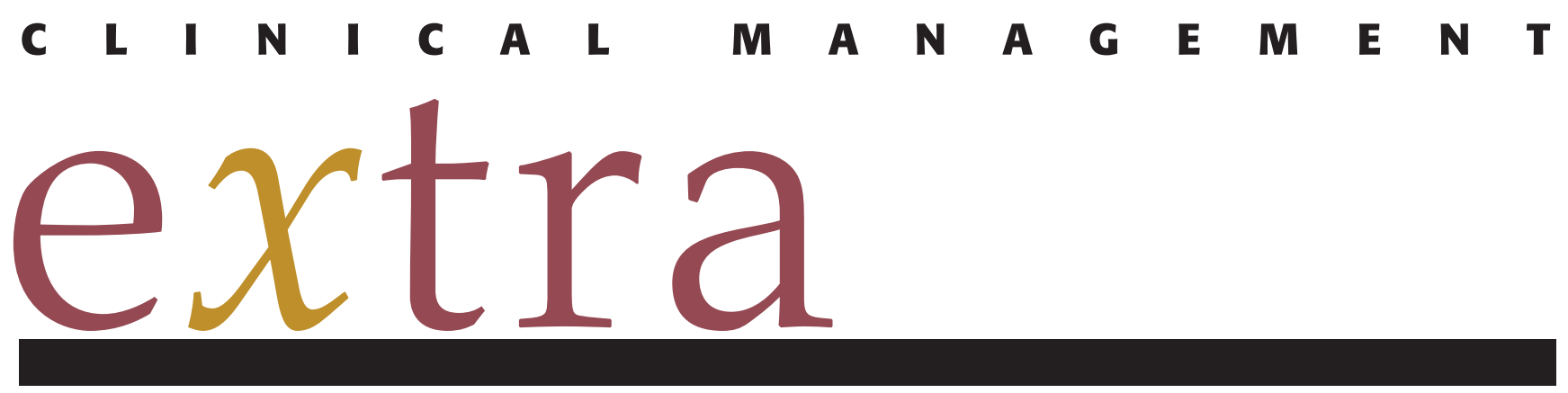

\title{
The Role of Therapeutic Angiogenesis in Tissue Repair and Regeneration
}
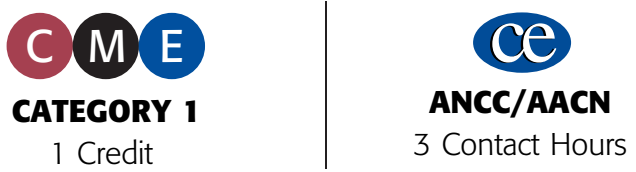

William W. Li, MD • President and Medical Director • The Angiogenesis Foundation • Cambridge, MA

Katherine E. Talcott, AB • Program Specialist • The Angiogenesis Foundation • Cambridge, MA

Amy W. Zhai, AB • Program Specialist • The Angiogenesis Foundation • Cambridge, MA

Erwin A. Kruger, MD • Resident Physician • Department of Surgery • University of California • Los Angeles, CA

Vincent W. Li, MD, MBA • Director • Angiogenesis Clinical Center • Division of Dermatology • Brigham \& Women's Hospital • Boston, MA • Board of Directors • Scientific Director • The Angiogenesis Foundation • Cambridge, MA

Dr William W. Li has disclosed that he is a consultant/advisor to Genentech and Medtronics, and is a member of the speakers' bureau for Johnson \& Johnson. Dr Vincent W. Li has disclosed that he is a consultant/advisor to Organogenesis, Genentech, and Medtronics, and is a member of the speakers' bureau for Johnson \& Johnson. The remaining authors have disclosed that they have no financial relationships with or interests in any commercial companies pertaining to this educational activity.

Wolters Kluwer Health has identified and resolved all faculty conflicts of interest regarding this educational activity.

The authors have disclosed that topical recombinant human vascular endothelial growth factor protein, vascular endothelial growth factor, trafermin, bone-marrow derived endothelial progenitor cells, and topical nerve growth factor have not been approved by the US Food and Drug Administration. The authors have disclosed that becaplermin has not been approved by the US Food and Drug Administration for use in the treatment of acute wound healing. Please consult product labeling for the approved usage of this drug or device. The authors have disclosed that rosuvastatin has not been approved by the US Food and Drug Administration for use in nerve regeneration. Please consult product labeling for the approved usage of this drug or device.

\section{PURPOSE}

To provide the physician and registered professional nurse with an understanding of angiogenesis and an overview of therapeutic angiogenesis modalities used to manage wounds and other tissue repair situations.

\section{TARGET AUDIENCE}

This continuing education activity is intended for physicians and nurses with an interest in learning more about angiogenesis and therapeutic angiogenesis modalities to manage wounds and other tissue repair situations. OBJECTIVES

After reading the article and taking the test, the participant should be able to:

1. Describe the basic principles of angiogenesis and its role in tissue repair and regeneration.

2. Identify the available therapeutic angiogenesis modalities and clinical issues surrounding their use. 
A ngiogenesis, the formation of new blood vessels from a preexisting vascular bed, plays a critical role in tissue growth and repair. New vessels deliver oxygen, micronutrients, and inflammatory cells to sites of injury. Endothelial cells comprising the vasculature release survival factors into regenerating tissues, enabling the expansion of cell mass by promoting cell proliferation and impeding cell death. As a result, angiogenesis serves as a regulatory mechanism for wound healing, hair and adipose growth, nerve regeneration, and muscle and bone repair.

Because the therapeutic control of angiogenesis is now being established in clinical practice, this review article will describe the basic principles of angiogenesis and its role in wound healing and specific forms of tissue regeneration, as well as identify available treatment modalities and clinical issues surrounding their use for tissue repair and regeneration.

\section{PHYSIOLOGIC CONTROL OF ANGIOGENESIS}

In healthy adults, angiogenesis is a rare occurrence that is limited to 4 major events: endometrial formation during the menstrual cycle, placenta formation during pregnancy, wound granulation after acute injury, and hair follicle vascularization during the anagen phase of the hair cycle. Except for these circumstances, the vascular endothelium is fairly inactive and has one of the lowest mitotic rates in the body, dividing as infrequently as once every 1000 days. ${ }^{1}$

The normally nonproliferative state of blood vessels is maintained physiologically through the balanced effects of angiogenesis stimulatory and inhibitory molecules present throughout the body (Table 1). Positive regulators include angiogenic growth factors that activate endothelial cells to undergo proliferation, migration, tube formation, and maturation at sites where angiogenesis is required. Negative regulators are a diverse group of molecules that block endothelial activation, proliferation, or participation in vascular growth.

Tissues requiring increased vascularity and perfusion upregulate the production of angiogenic growth factors, tipping the regulatory balance toward vessel growth. Cells associated with tissue repair, such as platelets, monocytes, and macrophages, also release angiogenic growth factors into injured regions. When the requirements for vascular growth have been fulfilled, the body returns to a steady state of angiogenesis suppression. This is achieved by a decrease in growth factor production, resolution of inflammation, and the restoration of dominant effects by increasing local levels of angiogenesis inhibitors.

Tissue hypoxia is a potent stimulus for angiogenesis. Low oxygen tension activates hypoxia-inducible transcription factors (HIF-1 $1 \alpha)$ that regulate cellular production of vascular

\section{Table 1. \\ ANGIOGENESIS REGULATORY MOLECULES}

\section{Endogenous Stimulators}

- Adrenomedullin

- Angiogenin

- Angiopoietin-1

- Angiopoietin-related growth factor

- Brain-derived neurotrophic factor

- Corticotropin-releasing hormone

- Cyr16

- Erythropoietin

- Fibroblast growth factors

- Follistatin

- Granulocyte colony stimulating factor

- Hepatocyte growth factor

- Interleukins (IL-3, IL-8)

- Midkine

- Nerve growth factor

- Neurokinin A

- Neuropeptide Y

- Placental growth factor

- Platelet-derived endothelial cell growth factor

- Platelet-derived growth factor

- Pleiotrophin

- Progranulin

- Proliferin

- Secretoneurin

- Substance P

- Transforming growth factor-alpha

- Transforming growth factor-beta

- Tumor necrosis factor-alpha

- Vascular endothelial growth factor

- VG5Q

Endogenous Inhibitors

- Angiostatin

- Canstatin

- Endostatin

- Fibronectin $20 \mathrm{kDa}$ fragment

- Interferons (alpha, beta, gamma)

- Interferon-inducible protein-10

- Interleukins (IL4, IL-10, IL-12)

- Kringle 5

- Maspin

- Meth-1, -2

- 2-methoxyestradiol

- Pigment epithelium-derived factor

- Plasminogen activator inhibitor

- Platelet factor-4

- Prolactin $16 \mathrm{Kd}$ kDa fragment

- Tetrahydrocortisol-S

- Thrombospondin-1

- Tissue inhibitors of matrix proteases

- Troponin-1

- Tumstatin

- Vasostatin 
endothelial growth factor (VEGF). ${ }^{2}$ When tissue normoxia is restored, a regulatory feedback loop terminates these signals.

In severe injury or ischemia leading to necrosis, dying cells release angiogenesis stimulatory factors from their intracellular space. The full extent of tissue death and survival is determined, in part, by the degree of angiogenic response that occurs in "watershed" or perimeter areas of ischemic injury. Newly formed capillaries in those areas undergo a maturation process, called arteriogenesis, to form arterioles and small arteries.

\section{STEPS OF NEW CAPILLARY GROWTH}

Angiogenesis occurs through a series of distinct molecular and cellular steps involving interactions between growth factors and receptors, endothelial cells, mesenchymal cells, and the extracellular matrix (ECM) within which capillaries are growing. Each step represents a potential point for therapeutic control, through stimulation or repression. These steps are as follows:

- Angiogenic growth factors are released by platelets, inflammatory cells, and ruptured cells. These factors activate endothelial cells in nearby venules by binding to cell surface receptors. This initiates cell signaling pathways by phosphorylation of receptor tyrosine kinases.

- Activated endothelial cells proliferate and bud outward through the vascular basement membrane. Capillary sprouts orient and migrate directionally toward the source of growth stimuli-the wound bed.

- Simultaneously, growth factors such as VEGF, placental growth factor (PlGF), and platelet-derived growth factor (PDGF) recruit hematopoietic vascular stem cells, called endothelial progenitor cells (EPCs) to the angiogenic site. ${ }^{3-5}$ The bone marrow serves as a reservoir for EPCs that can be mobilized into the circulation, moving toward and incorporating into growing microvessels. The homing mechanisms of EPCs involve expression of the receptor CXCR4 by mobilized EPCs, and expression of the CXCR4 ligand, SDF-1 (stromal cell-derived factor 1), by activated endothelial cells within the growing vessel. ${ }^{6}$

- Capillary extension is mediated by adhesion molecules (integrins $\alpha_{v} \beta_{3}, \alpha_{v} \beta_{5}$, and $\alpha_{5} \beta_{1}$ ) expressed on the cell surface of migrating endothelium. ${ }^{7}$ Integrins anchor cells to the surrounding ECM, and this interaction activates survival signals within the cell. Proteolytic enzymes are released at the growing tips of capillaries, dissolving the ECM at the advancing vascular front. Specialized endothelial cells, called "tip cells," form a growth cone that extend filopodia as sensors and guide the navigation of extending vessels. ${ }^{8}$ These sensors use the Robo- 1 and Robo- 4 receptors to detect attractive cues, such as VEGF, and repulsive cues, such as Sema3A, in their microenvironment.

- Vascular tubes and loops are formed by specific cell-cell and cell-matrix signals. ${ }^{9}$ Specialized protein-receptor (ephrin/ EphR) interactions guide the patterning of the new vascular network into arterial and venous channels. ${ }^{10}$

- Maturation of a new vessel occurs with recruitment of smooth muscle cells and pericytes to form a covering around the capillary. ${ }^{11}$ These periendothelial cells assist in stabilizing the vessel architecture. Blood flow then occurs.

Delivery of vascular
endothelial growth factor
to injured and ischemic
tissue has been found
to induce angiogenesis,
collateralization, and
regeneration of skin, nerves,
soft tissue, and bone.

\section{PLATELETS AND GROWTH FACTORS}

\section{Platelets}

Platelets play a critical early role in angiogenesis during tissue repair. Immediately following injury, angiogenesis is initiated by platelets during the hemostatic phase of wound healing. Platelets contain numerous angiogenic growth factors, including VEGF, PDGF, and fibroblast growth factors (FGFs). These are degranulated into the wound bed as hemostasis is achieved. Because platelets are present in numbers far in excess of hemostatic requirements in healthy individuals $\left(2 \times 10^{9}\right.$ produced/day $)$, recent studies suggest that platelets perform a surveillance function by trafficking growth factors to sites of microscopic injury or tissue remodeling. ${ }^{12}$

Platelets also contain angiogenesis inhibitors, and at least one inhibitor, endostatin, is counter-regulated by exchange with VEGF. ${ }^{12,13}$ Therefore, platelets may play a role in terminating angiogenesis independent of hemostasis.

\section{Vascular endothelial growth factor}

Vascular endothelial growth factor, also known as vascular permeability factor, is one of the best-studied angiogenic growth factors. ${ }^{14}$ The biologic activities of VEGF include stimulation of angiogenesis, control of capillary leaking, survival 
signaling for vascular cells and neurons, chemotaxis of inflammatory cells, recruitment of EPCs from bone marrow, induction of lymphangiogenesis (via specific VEGF family members), and up-regulation of other angiogenic factors, such as FGF, PDGF, and epidermal growth factor. Vascular endothelial growth factor is highly expressed by keratinocytes in wounded skin. ${ }^{15}$ The experimental delivery of VEGF to injured and ischemic tissue induces angiogenesis, collateralization, and regeneration of skin, nerves, soft tissue, and bone. ${ }^{16-20}$

Recombinant human VEGF protein is being evaluated as a topical therapy for diabetic foot ulcers, and gene delivery of VEGF is under clinical investigation for arterial ulcer healing in patients with limb ischemia.

\section{Platelet-derived growth factor}

Platelet-derived growth factor is a pluripotent angiogenic growth factor that also mediates collagen production from fibroblasts, stem cell recruitment from bone marrow, lymphatic growth, and inflammatory cell chemotaxis. Plateletderived growth factor works synergistically with the other growth factors, such as VEGF and FGF, to promote vascular maturation by recruiting smooth muscle cells and pericytes to newly sprouted vessels. ${ }^{21-23}$ Deficiencies in PDGF expression are a characteristic of diabetic wounds, and local delivery of PDGF protein or gene can augment and restore diabetic defects in wound granulation. ${ }^{5,24} \mathrm{~A}$ topical recombinant human form of PDGF-BB (becaplermin [RE-

GRANEX] 0.01\% gel; Johnson \& Johnson Wound Management, Somerville, NJ) was approved by the Food and Drug Administration (FDA) in 1997, and is in clinical use for treatment of diabetic foot ulcers. ${ }^{25}$

\section{Fibroblast growth factors}

Fibroblast growth factors are a large family of proteins that stimulate cell proliferation and survival in endothelium, fibroblasts, neurons, myocytes, epidermis, and osteocytes. Cell damage releases FGFs into injured tissue. Experimentally delivered FGF-1 and FGF-2 have been shown to stimulate angiogenesis and improve perfusion in ischemic limbs, wounds, myocardium, and the brain. ${ }^{26-30}$ Fibroblast growth factor-7, also known as keratinocyte growth factor, stimulates angiogenesis and epithelial cell proliferation in cutaneous wounds. ${ }^{31,32}$ A human recombinant form of FGF-2 (trafermin [Fiblast]; Kaken Pharmaceutical Co., Ltd, Tokyo, Japan) became available in 2001 in Japan, and it has been used clinically to treat burn injury and other types of wounds. ${ }^{33-35}$

\section{Endothelial progenitor cells}

Vascular stem cells have been identified within the peripheral circulation in bone marrow and in adipose tissue. ${ }^{36,37}$ Adult bone marrow contains vast stores of hemapoietic stem cells with the potential to differentiate into adult vascular cells once mobilized. Tissue injury releases growth factors-VEGF, PIGF, PDGF- that reach the sinusoidal circulation in the bone marrow.

Then, VEGF activates its receptor VEGFR-1 in the osteoclastic niche in the bone marrow, setting off a cascade of events that includes the production of matrix matalloprotease-9, cleavage of the membrane-bound $\mathrm{m}$-kit ligand to generate the soluble form of s-kit, and release of EPCs from the vascular bone marrow niche into the systemic circulation. The mobilized EPCs move in and take part in the expanding angiogenic network of blood vessels. Bone marrow-derived EPCs have been clinically administered to induce lower extremity angiogenesis and to heal ischemic ulcers in patients with end-stage peripheral arterial disease for whom no other treatment option existed. ${ }^{38}$

\section{THERAPEUTIC ANGIOGENESIS FOR TISSUE REPAIR}

Therapeutic angiogenesis is the delivery of biologic agents, small molecules, genes, or cells or the use of mechanical devices to stimulate reparative blood vessel growth in injured, hypoxic, or ischemic tissues to restore form and function. Beginning in the early 1990s, efforts to develop therapeutic angiogenesis have been directed at wound healing, coronary disease, and limb ischemia. Newer applications focus on nerve growth, hair growth, flap revascularization, and organ tissue engineering. Although efforts to develop therapeutic angiogenesis for cardiovascular disease have been met by considerable challenges, many angiogenesis-stimulating 


\section{Figure 1.}

\section{WOUND ANGIOGENSIS}

Wound angiogenesis in a fully healed murine acute wound treated with daily topical rhPDGF-BB $0.01 \%$. Vessels shown are on the ventral aspect of an exposed skin flap containing the entire healed wound. Note the radial convergence of new blood vessels emerging from larger vessels towards the central wound region.

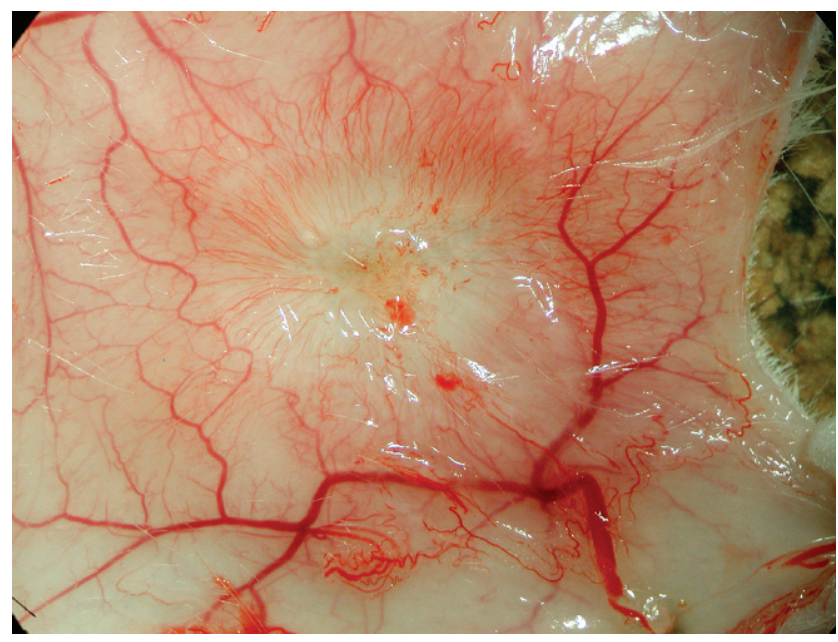

C 2005 The Angiogenesis Foundation. Used with permission.

therapeutic products and devices are successful in clinical use for wound care.

\section{WOUND HEALING}

Modern wound practice incorporates a growing number of angiogenesis-stimulating advanced modalities. These include recombinant growth factors, tissue-engineered products whose cells release growth factors into the wound bed, hyperbaric oxygen, low-intensity ultrasound, and negative pressure wound therapy. These strategies have been developed primarily as adjunctive advanced modalities for treating nonhealing wounds.

Recent studies suggest that therapeutic angiogenesis may accelerate healing of acute wounds. In two clinical studies, for example, topical recombinant PDGF-BB (becaplermin) was applied to full-thickness punch biopsies to evaluate whether growth factor therapy can accelerate normal healing. ${ }^{39,40}$ As a group, PDGF-treated wounds completely closed by as much as $30 \%$ faster than control wounds treated with bacitracin ointment.

Wound healing velocity was evaluated, and wounds treated with PDGF also showed a faster healing velocity from the outset of treatment, as well as increased angiogenesis, com-

pared with the controls ${ }^{39,40}$ (Figure 1). The delivery of topical PDGF-BB appears to accelerate physiologic rates of healing, requiring a reexamination of the surgical doctrine that normal wounds heal at their optimal rate.

Histologic analysis of PDGF-treated acute wounds demonstrated increased microvessel density and collagen deposition. ${ }^{41}$ This indicates that therapeutic angiogenesis may have a clinical benefit in situations where faster healing is desirable, such as following hip replacement surgery, episiotomy, and cesarean section, and in sports or military injuries.

For chronic wound therapy, therapeutic angiogenesis addresses delayed or inadequate granulation. Specific angiogenesis defects are present in common chronic wounds.

\section{Table 2.}

\section{PATIENT FACTORS AND MEDICATIONS KNOWN TO INHIBIT ANGIOGENESIS}

Patient factors

- Increased age

- Hypercholesterolemia

- Alcohol use

- Diabetes

Prescription medications

- Antibiotics (clarithromycin, doxycycline, tetracycline)

- Antihypertensive agents (captopril, enalapril, metoprolol)

- Diuretics (bumetanide, furosemide)

- Nonsteroidal anti-inflammatory drugs

- COX-2 inhibitors (celecoxib)

- PPAR- $\gamma$ agonists (pioglitazone, rosiglitazone)

Oncology agents

- Adriamycin*

- Cyclophosphamide*

- Docetaxel ${ }^{\star}$

- Doxorubicin*

- Interferon alpha

- Methotrexate*

- Paclitaxel

- Thalidomide

- Topotecan*

- Trastuzumab

- Vinblastine*

Advanced molecular targeting drugs

Cancer therapies

- Bevacizumab

Arthritis agents

- Etanercept

- Infliximab

*At low-dose metronomic scheduling.

Source: The Angiogenesis Foundation (http://www.angio.org); used with permission. 
Diabetes is associated with growth factor deficiencies, abnormal microvascular architecture, and depressed bone marrow reservoirs of EPCs. ${ }^{5,24,42}$ Persons with diabetes also accumulate advanced glycation end-products in their tissues, which have been shown to inhibit angiogenesis and cause end-organ damage in diabetes. ${ }^{43}$ Venous leg ulcers develop granulation tissue with abnormal glomeruloid vessels that perfuse poorly, leading to tissue hypoxia and increased VEGF production, but decreased $\mathrm{TcPO}_{2}$. Vascular endothelial growth factor induces increased hyperpermeability in venous leg ulcers, resulting in wound fluid exudation and extravasation of fibrin that traps growth factors and limits their availability for cell stimulation.

Angiogenesis is impaired with advanced age and by hypercholesterolemia, alcohol consumption, and certain commonly prescribed medications, such as nonsteroidal antiinflammatory drugs, COX-2 inhibitors, PPAR $-\gamma$ agonists (rosiglitazone), diuretics (bumetanide, furosemide), and antihypertensive agents (captopril, enalapril, metoprolol) $^{44}$ (Table 2). Advanced wound care modalities that stimulate angiogenesis overcome these impediments to promote healing.

Following is a discussion of several of these modalities.

- Growth factor therapy. Topical recombinant human PDGFBB (becaplermin) was the first pharmaceutical growth factor to be approved by the FDA for wound care, and it is currently the only prescription drug indicated for treating diabetic lower-extremity ulcers. In a study of 251 patients with diabetes, ${ }^{45}$ complete healing was accelerated when use of rhPDGF-BB was combined with best clinical care. The number of ulcer-days per patient per year was reduced, with attendant cost savings per ulcer-day averted, compared with best clinical care alone. ${ }^{45}$ The efficacy of rhPDGF-BB depends on good wound care practices, including infection control, appropriate off-loading, maintenance of wound moisture balance, and sharp debridement. Sharp debridement is required to expose growth factor receptors, as well as for removing necrotic tissue and eschar, senescent cells, and bacteria.

Control of protease activity in wound fluid is also important for preventing growth factor degradation. An oxidized regenerated cellulose/bovine collagen dressing (ORC/collagen; Promogran Matrix Wound Dressing; Johnson \& Johnson
Wound Management) neutralizes proteases in wound fluid and decreases wound surface area. ${ }^{46-48}$ The ORC/collagen dressing can be clinically combined with rhPDGF-BB to protect the topically applied growth factor. A related product (PRISMA Matrix; Johnson \& Johnson Wound Management) combines $1 \%$ silver with the ORC/collagen for antimicrobial action in addition to protease control and growth factor protection. This advanced dressing integrates protease inhibition, growth factor protection, and antibacterial functions into a single product that can be successfully used with becaplermin.

- Tissue-engineered products. Several available tissueengineered products have been shown to stimulate angiogenesis in wounds. Cellular products (Apligraf; Organogenesis, Inc, Canton, MA, and Dermagraft; Smith \& Nephew, Largo, FL) and acellular products (OASIS Wound Matrix; HEALTHPOINT, Ltd, Fort Worth, TX) are used in wound care clinics. In combination with good wound care practices, all three products have demonstrated efficacy in healing chronic wounds. ${ }^{49-}$ 52 These products contain and release multiple growth factors, such as VEGF, FGF, PDGF, and transforming growth factor- $\beta$ (TGF $\beta$ ), into the wound bed after topical application. $^{53-55}$ The biomaterial or matrix may be adsorbed into the wound bed, and repeated applications advance healing.

Although hypothesized, it has not been clinically proven that the delivery of multiple growth factors by tissue-engineered products offers an advantage over treatments based on a single growth factor, such as rhPDGF-BB. A randomized clinical trial comparing the OASIS Wound Matrix to rhPDGF-BB in 73 patients with diabetic lower-extremity ulcers showed no statistically significant advantage achieved by the tissueengineered product in terms of incidence of complete healing at 12 weeks. $^{56}$

- Platelet products. Autologous platelet preparations are used clinically for healing of acute/surgical and chronic wounds. These topical treatments deliver the contents of platelets and other cells harvested from patients to their own wounds. Cytokine arrays and immunoassays have been used to profile and quantify angiogenic growth factors present in platelet-rich plasma. ${ }^{57}$ A spectrum of growth factors is also present, including basic FGF, VEGF, and PDGF. An important finding in patient samples is the interindividual variation of growth 


\section{Table 3. \\ GROWTH FACTOR-TARGETING ANTIANGIOGENIC AGENTS IN CLINICAL USE OR LATE STAGE DEVELOPMENT}

\begin{tabular}{|c|c|c|}
\hline Name & Target(s) & Developer \\
\hline Bevacizumab & VEGF & Genentech \\
\hline Cetuximab & EGF & ImClone Systems \\
\hline Erlotinib & EGF & Roche/Genentech \\
\hline Etanercept & $\mathrm{TNF} \alpha$ & Amgen \\
\hline Gefitinib & EGF & AstraZeneca \\
\hline Infliximab & $\mathrm{TNF} \alpha$ & Centocor \\
\hline Lenalidomide & VEGF, bFGF, TNF $\alpha$ & Celgene Corporation \\
\hline Pegatanib & VEGF & $\begin{array}{l}\text { EyeTech } \\
\text { Pharmaceuticals }\end{array}$ \\
\hline Ranibizumab & VEGF & Genentech \\
\hline Sorafenib & $\begin{array}{l}\text { VEGF, PDGF, } \\
\text { Raf kinase }\end{array}$ & Bayer Corporation \\
\hline Sunitanib & $\begin{array}{l}\text { VEGF, PDGF, } \\
\text { c-kit, flt3 }\end{array}$ & Pfizer \\
\hline Thalidomide & VEGF, bFGF, TNF $\alpha$ & Celgene Corporation \\
\hline Vatalanib & VEGF, PDGF, c-kit & Novartis \\
\hline
\end{tabular}

factor levels. The levels of platelet-derived antiangiogenic molecules have not yet been profiled in autologous platelet preparations.

Well-designed clinical studies are under way to determine the efficacy of platelet products to improve healing of acute surgical wounds and chronic wounds. The determination of growth factor levels and their biologic activity in autologous platelet products derived from patients with chronic wounds will need to be established if such patients produce defective platelets, have decreased growth factor levels, or have impaired biologic activity in their growth factors.

- Other devices. Hyperbaric oxygen therapy (HBO) improves tissue oxygenation and promotes improved healing in chronic wounds. ${ }^{58}$ An important mechanism of $\mathrm{HBO}$ therapy is the stimulation of angiogenesis by up-regulating growth factor receptors and hypoxia-inducible transcription factors in wound tissue. ${ }^{59}$ This becomes most pronounced between treatment periods when tissue hypoxia becomes exaggerated between hyperoxic dives. Use of negative pressure wound therapy (V.A.C. Therapy; KCI USA, San Antonio, TX, and Versatile 1 Wound Vacuum System; BlueSky Medical, Carlsbad, CA) also stimulates wound angiogenesis. ${ }^{60,61}$ Applied subatmospheric pressure induces a $5 \%$ to $10 \%$ me- chanical strain on cells in the wound bed, deforming their shape and stimulating DNA synthesis and cell proliferation. ${ }^{62}$ Low-frequency ultrasound (MIST Therapy System; Celleration, Inc, Eden Prairie, MN, and Sonoca 180; Soring, Inc, Fort Worth, TX) applied to chronic wound tissue also has been shown to stimulate angiogenesis as a mechanism for healing. ${ }^{63}$

\section{WOUND HEALING COMPLICATIONS}

A new class of drugs, called antiangiogenic agents, may be problematic in wound healing. Many of these agents target growth factors and neutralize their cellular effects to inhibit pathologic angiogenesis in conditions such as cancer and age-related macular degeneration (Table 3). However, these antiangiogenic agents may also delay wound healing.

The first antiangiogenic drug to be approved for oncology is bevacizumab (Avastin; Genentech, Inc, San Francisco, CA), a monoclonal antibody that targets VEGF and is effective for treating colorectal, breast, and non-small cell lung cancer. In clinical trials, use of bevacizumab has resulted in wound healing complications, including dehiscence of surgical incisions and intestinal perforations in patients with colorectal

\section{Figure 2. \\ VEGF GENE TRANSFER}

The perineural vasculature (vasa nervorum) is decreased in diabetic mice and improved with the delivery of VEGF via gene transfer. Longitudinal and cross-sectional views of the sciatic nerve from a nondiabetic animal show normal vascularity $(a, d)$. The sciatic nerve from a diabetic animal shows an irregular microcirculatory pattern and areas that are sparsely vascularized (b, e). The diabetic animal treated with VEGF gene transfer exhibits nerve angiogenesis and restored nerve conduction velocity (not shown).

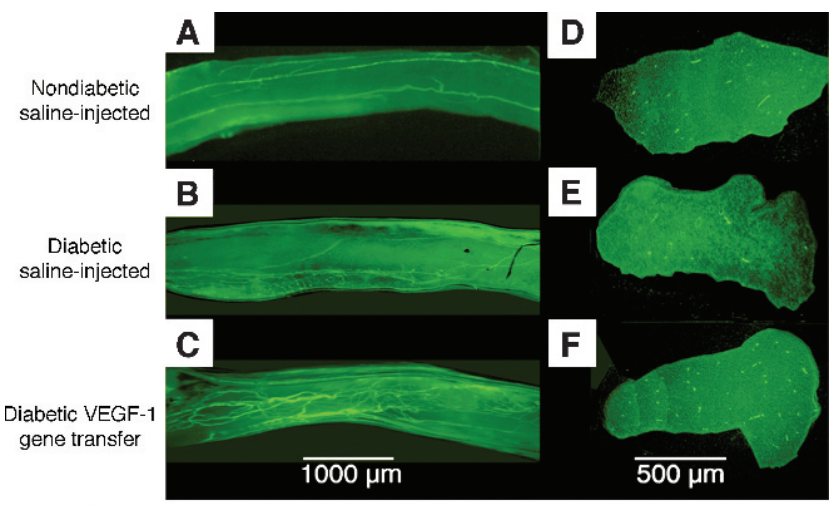

Source: Schratzberger P, Walter DH, Rittig K, et al. Reversal of experimental diabetic neuropathy by VEGF gene transfer. J Clin Invest 2001;107:1083-92. Reprinted with permission. 
cancer. ${ }^{64,65}$ The clinical impact of bevacizumab on chronic wound healing has not yet been established, although slower diabetic wound healing has been anecdotally observed in cancer patients on bevacizumab.

Wound care specialists should be cautious with patients who are receiving an antiangiogenic agent. Although discontinuation of a systemic antiangiogenic therapy is not medically advisable, delivery of a local angiogenesis-stimulating modality to a wound, such as growth factor therapy, may help overcome the angiogenesis inhibitor's effects on wound healing.

\section{NERVE REGENERATION}

Angiogenesis is closely linked to nerve growth, regeneration, and survival. In fact, a growing number of preclinical and early clinical studies demonstrate that therapeutic angiogenesis can promote both repair and regeneration after nerve injury in the peripheral and central nervous systems.

The effects of angiogenesis stimulation on nerve injury appears to involve at least two mechanisms: improved microvascular perfusion of nerves and direct activation of neuronal receptors leading to nerve proliferation and survival. ${ }^{66}$ A third mechanism may be related to recruitment of neural stem cells to sites of nerve damage. ${ }^{67}$

Vascular endothelial growth factor is the best-studied angiogenic growth factor in the context of nerve repair and regeneration. Vascular endothelial growth factor and its receptor, VEGFR-2, are expressed by endothelial cells of the vasa nervorum-the capillary network supplying peripheral nerves-and also by Schwann cells, spinal axons, cortical neurons, and the retina. Experimental delivery of VEGF stimulates axonal outgrowth, but its deletion in animal models leads to decreased neural blood flow and nerve degeneration. ${ }^{68,69}$

Vascular endothelial growth factor is expressed by astrocytes after spinal cord injury. It has autocrine neuroprotective effects by binding to VEGFR-2, activating survival pathways (Akt, NFкB) to prevent nerve cell apoptosis. ${ }^{66,70}$

Despite today's medical advances, the treatment of diabetic neuropathy remains a major unmet need: $7 \%$ of individuals with diabetes develop some form of polyneuropathy within 1 year of diagnosis, and 50\% develop neuropathy after 25 years of having diabetes. ${ }^{71}$

Therapeutic angiogenesis holds promise for the peripheral sensory, wound, and urologic complications of diabetes. In diabetic mice models, the development of neuropathy has been correlated with significant impairment of the sciatic nerve vasa nervorum, with a $32 \%$ decrease in vessel density, a $33 \%$ decrease in cross-sectional vessel size, and a decrease in nerve blood flow by laser Doppler assessment compared with nondiabetic control mice. ${ }^{72}$

In trials, delivery of three different proangiogenic agents (VEGF, rosuvastatin [Crestor], Sonic hedgehog) restored neuronal blood flow and improved nerve conduction velocity in mice with diabetes (Figure 2). ${ }^{71-73}$ Vascular endothelial growth factor delivered to animals with neuropathy induced by chemotherapy (cisplatin) resulted in preservation of nerve blood flow and prevention of nerve deterioration. ${ }^{74}$ Similarly, VEGF and another angiogenic factor, brain-derived neurotrophin factor, applied to crushed nerves in the pelvic ganglia, ameliorated erectile dysfunction and facilitated neuronal regeneration in experimental rats, even when applied 1 month after injury. ${ }^{75}$

In clinical studies of patients with peripheral arterial disease, VEGF gene transfer revealed objective improvements in preexisting sensory neuropathy after therapeutic angiogenesis. Based on these observations, 192 patients have been participating in a randomized, double-blind, placebo-controlled clinical trial at Caritas St. Elizabeth's Medical Center in Boston, MA. The purpose is to study VEGF gene transfer as a strategy to reverse diabetic neuropathy.

Topical nerve growth factor, which stimulates angiogenesis and nerve growth, has also been reported to promote healing in human diabetic lower-extremity wounds. ${ }^{76}$

\section{CONCLUSION}

Therapeutic angiogenesis is a proven clinical strategy for promoting faster wound healing in diabetic foot ulcers and other wounds with delayed healing. Because the microvasculature plays a physiologic role in nerve growth and neuronal maintenance, stimulation of angiogenesis may also be useful for ameliorating nerve injury, such as diabetic neuropathy. As researchers continue to unravel the mechanisms for healing and regeneration, clinicians will have the opportunity to apply the principles of angiogenesis to restore form and function to tissues, including skin, nerves, and other end-organs.

\section{REFERENCES}

1. Folkman J. Antiangiogenesis agents. In: DeVita VT, Hellman S, Rosenberg SA, eds. Cancer: Principles \& Practice in Oncology. 6th ed. Philadelphia, PA: Lippincott Williams \& Wilkins; 2001.

2. Maxwell PH, Ratcliffe PJ. Oxygen sensors and angiogenesis. Semin Cell Dev Biol 2002;13:29-37.

3. Tepper OM, Capla JM, Galiano RD, et al. Adult vasculogenesis occurs through in situ recruitment, proliferation, and tubulization of circulating bone marrow-derived cells. Blood 2005;105:1068-77.

4. Hattori $\mathrm{K}$, Heissig B, Wu Y, et al. Placental growth factor reconstitutes hematopoiesis by recruiting VEGFR1(+) stem cells from bone-marrow microenvironment. Nat Med 2002;8:841-9. 
5. Keswani SG, Katz AB, Lim FY, et al. Adenoviral mediated gene transfer of PDGF-B enhances wound healing in type I and type II diabetic wounds. Wound Repair Regen 2004;12:497-504.

6. Yamaguchi J, Kusano KF, Masuo 0, et al. Stromal cell-derived factor-1 effects on ex vivo expanded endothelial progenitor cell recruitment for ischemic neovascularization. Circulation 2003;107:1322-8.

7. Ruegg C, Mariotti A. Vascular integrins: pleiotropic adhesion and signaling molecules in vascular homeostasis and angiogenesis. Cell Mol Life Sci 2003;60:1135-57.

8. Autiero $M$, De Smet F, Claes F, Carmeliet $P$. Role of neural guidance signals in blood vessel navigation. Cardiovasc Res 2005;65:629-38.

9. Nguyen M, Folkman J, Bischoff J. 1-Deoxymannojirimycin inhibits capillary tube formation in vitro. Analysis of $\mathrm{N}$-linked oligosaccharides in bovine capillary endothelia cells. J Biol Chem 1992;267:26157-65.

10. Cheng N, Brantley DM, Chen J. The ephrins and Eph receptors in angiogenesis. Cytokine Growth Factor Rev 2002;13:75-85.

11. Darland DC, D'Amore PA. Blood vessel maturation: vascular development comes of age J Clin Invest 1999;103:157-8.

12. Ma L, Perini R, McKnight W, et al. Proteinase-activated receptors 1 and 4 counterregulate endostatin and VEGF release from human platelets. Proc Natl Acad Sci USA 2005;102:216-20.

13. Staton CA, Lewis CE. Angiogenesis inhibitors found within the haemostasis pathway $\mathrm{J}$ Cell Mol Med 2005;9:286-302.

14. Tammela T, Enholm B, Alitalo K, Paavonen K. The biology of vascular endothelial growth factors. Cardiovasc Res 2005;65:550-63.

15. Brown LF, Yeo KT, Berse B, et al. Expression of vascular permeability factor (vascular endothelial growth factor) by epidermal keratinocytes during wound healing. J Exp Med 1992;176:1375-9.

16. Galiano RD, Tepper OM, Pelo $\mathrm{CR}$, et al. Topical vascular endothelial growth factor accelerates diabetic wound healing through increased angiogenesis and by mobilizing and recruiting bone marrow-derived cells. Am J Pathol 2004;164:1935-47.

17. Efthimiadou A, Asimakopoulos B, Nikolettos N, et al. The angiogenetic effect of intramuscular administration of VEGF on muscle: the influence of exercise on angiogenesis. In Vivo 2004;18:825-9.

18. Storkebaum $E$, Lambrechts $D$, Carmeliet $P$. VEGF: once regarded as a specific angiogenic factor, now implicated in neuroprotection. BioEssays 2004;26:943-54.

19. Fiedler J, Leucht F, Waltenberger J, Dehio C, Brenner RE. VEGF-A and PIGF-1 stimulate chemotactic migration of human mesenchymal progenitor cells. Biochem Biophys Res Commun 2005;334:561-8

20. Ito $\mathrm{H}$, Koefoed M, Tiyapatanaputi $\mathrm{P}$, et al. Remodeling of cortical bone allografts mediated by adherent rAAV-RANKL and VEGF gene therapy. Nat Med 2005;11:291-7.

21. Cao R, Brakenhielm E, Pawliuk R, et al. Angiogenic synergism, vascular stability and improvement of hind-limb ischemia by a combination of PDGF-BB and FGF-2. Nat Med 2003;9:604-13.

22. Lindahl $P$, Johansson BR, Leveen $P$, Betsholtz $C$. Pericyte loss and microaneurysm formation in PDGF-B-deficient mice. Science 1997;277:242-5

23. Hirschi KK, Rohovsky SA, Beck LH, Smith SR, D'Amore PA. Endothelial cells modulate the proliferation of mural cell precursors via platelet-derived growth factor-BB and heterotypic cell contact. Circ Res 1999;84:298-305.

24. Doxey DL, Ng MC, Dill RE, lacopino AM. Platelet-derived growth factor levels in wounds of diabetic rats. Life Sci 1995;57:1111-23.

25. Wieman TJ, Smiell JM, Su Y. Efficacy and safety of a topical gel formulation of recombinant human platelet-derived growth factor-BB (becaplermin) in patients with chronic neuropathic diabetic ulcers. A phase III randomized placebo-controlled double-blind study. Diabetes Care 1998;21:822-7.

26. Comerota AJ, Throm RC, Miller KA, et al. Naked plasmid DNA encoding fibroblast growth factor type 1 for the treatment of end-stage unreconstructible lower extremity ischemia: preliminary results of a phase I trial. J Vasc Surg 2002;35:930-6.

27. Obara K, Ishihara M, Fujita M, et al. Acceleration of wound healing in healing-impaired $\mathrm{db} / \mathrm{db}$ mice with a photocrosslinkable chitosan hydrogel containing fibroblast growth factor-2. Wound Repair Regen 2005;13:390-7.

28. Stegmann TJ. FGF-1: a human growth factor in the induction of neoangiogenesis. Expert Opin Investig Drugs 1998;7:2011-5.

29. Post MJ, Laham R, Sellke FW, Simons M. Therapeutic angiogenesis in cardiology using protein formulations. Cardiovasc Res 2001;49:522-31.

30. Kawamata T, Speliotes EK, Finklestein SP. The role of polypeptide growth factors in recovery from stroke. Adv Neurol 1997;73:377-82.
31. Gillis P, Savla U, Volpert OV, et al. Keratinocyte growth factor induces angiogenesis and protects endothelial barrier function. J Cell Sci 1999;112:2049-57.

32. Kopp J, Wang GY, Kulmburg P, et al. Accelerated wound healing by in vivo application of keratinocytes overexpressing KGF. Mol Ther 2004;10:86-96.

33. Fu X, Shen Z, Chen Y, et al. Randomised placebo-controlled trial of use of topical recombinant bovine basic fibroblast growth factor for second-degree burns. Lancet 1998; 352:1661-4

34. Fu X, Shen Z, Chen Y, et al. Recombinant bovine basic fibroblast growth factor accelerates wound healing in patients with burns, donor sites and chronic dermal ulcers. Chin Med J (Engl) 2000;113:367-71.

35. Ichioka S, Ohura N, Nakatsuka T. The positive experience of using a growth factor product on deep wounds with exposed bone. J Wound Care 2005;14:105-9.

36. Takahashi T, Kalka C, Masuda H, et al. Ischemia- and cytokine-induced mobilization of bone marrow-derived endothelial progenitor cells for neovascularization. Nat Med 1999; 5:434-8.

37. Rehman J, Traktuev D, Li J, et al. Secretion of angiogenic and antiapoptotic factors by human adipose stromal cells. Circulation 2004;109:1292-8.

38. Tateishi-Yuyama E, Matsubara H, Murohara T, et al. Therapeutic Angiogenesis using Cell Transplantation (TACT) Study Investigators. Therapeutic angiogenesis for patients with limb ischaemia by autologous transplantation of bone-marrow cells: a pilot study and a randomised controlled trial. Lancet 2002;360:427-35.

39. Cohen MA, Eaglstein WH. Recombinant human platelet-derived growth factor gel speeds healing of acute full-thickness punch biopsy wounds. J Am Acad Dermatol 2001;45: $857-62$.

40. Serena T. Studies of growth factor therapy for acute wound healing In the human forearm biopsy model. Wound Healing Cooperative Group. Proceedings of the Symposium on Advanced Wound Care. Orlando, FL; 2004.

41. Li W. Angiogenesis and growth factors: what's new in research and in clinical practice. Wound Healing Cooperative Group. Proceedings of the Symposium on Advanced Wound Care. San Diego, CA; 2005.

42. Seitz S, Syed Ali S, Strodter D. Angioarchitecture in the heart of rats with streptozotocininduced diabetes mellitus. Ann Anat 1993;175:285-9.

43. Kuzuya M, Satake S, Ai S, et al. Inhibition of angiogenesis on glycated collagen lattices. Diabetologia 1998;41:491-9.

44. Simons M, Bonow R0, Chronos NA, et al. Clinical trials in coronary angiogenesis: issues, problems, consensus: an expert panel summary. Circulation 2000;102 E73-86.

45. Sibbald RG, Torrance G, Hux M, Attard C, Milkovich N. Cost-effectiveness of becaplermin for nonhealing neuropathic diabetic foot ulcers. Ostomy Wound Manage 2003:49 (11):76-84.

46. Cullen B, Smith R, McCulloch E, SilcockD, Morrison L. Mechanism of action of PROMOGRAN, a protease modulating matrix, for the treatment of diabetic foot ulcers. Wound Repair Regen 2002;10:16-25.

47. Cullen $B$, Watt PW, Lundqvist $C$, et al. The role of oxidised regenerated cellulose/collagen in chronic wound repair and its potential mechanism of action. Int J Biochem Cell Biol 2002;34:1544-56.

48. Vin F, Teot L, Meaume S. The healing properties of Promogran in venous leg ulcers. J Wound Care 2002;11:335-41.

49. Brem H, Kirsner RS, Falanga V. Protocol for the successful treatment of venous ulcers. Am J Surg 2004;188(Suppl 1A):1-8.

50. Fivenson D, Scherschun L. Clinical and economic impact of Apligraf for the treatment of nonhealing venous leg ulcers. Int J Dermatol 2003;42:960-5.

51. Marston WA, Hanft $J$, Norwood $P$, Pollak R. The efficacy and safety of Dermagraft in improving the healing of chronic diabetic foot ulcers: results of a prospective randomized trial. Dermagraft Diabetic Foot Ulcer Study Group. Diabetes Care 2003; 26:1701-5.

52. Mostow EN, Haraway GD, Dalsing M, Hodde JP, King D. Effectiveness of an extracellular matrix graft (OASIS Wound Matrix) in the treatment of chronic leg ulcers: a randomized clinical trial. OASIS Venus Ulcer Study Group. J Vasc Surg 2005;41:837-43.

53. Streit M, Braathen LR. Apligraf-a living human skin equivalent for the treatment of chronic wounds. Int J Artif Organs 2000;23:831-3.

54. Mansbridge J, Liu K, Patch R, Symons K, Pinney E. Three-dimensional fibroblast culture implant for the treatment of diabetic foot ulcers: metabolic activity and therapeutic range. Tissue Eng 1998;4:403-14

55. Hodde JP, Ernst DM, Hiles MC. An investigation of the long-term bioactivity of endogenous growth factor in OASIS Wound Matrix. J Wound Care 2005;14:23-5. 
56. Niezgoda JA, Van Gils CC, Frykberg RG, Hodde JP. Randomized clinical trial comparing OASIS wound matrix to Regranex gel for diabetic ulcers. OASIS Diabetic Study Group. Adv Skin Wound Care 2005;18:258-66.

57. Huang TC, Kanayinkal T, Laudenbach A. Cytokine profile and autologous gel. Proceedings of the Symposium for Advanced Wound Care San Diego, CA; 2005.

58. Strauss MB. Hyperbaric oxygen as an intervention for managing wound hypoxia: its role and usefulness in diabetic foot wounds. Foot Ankle Int 2005;26:15-8.

59. Sheikh AY, Rollins MD, Hopf HW, Hunt TK. Hyperoxia improves microvascular perfusion in a murine wound model. Wound Repair Regen 2005;13:303-8.

60. Venturi ML, Attinger CE, Mesbahi AN, Hess CL, Graw KS. Mechanisms and clinical applications of the vacuum-assisted closure (VAC) device: a review. Am J Clin Dermatol 2005; 6:185-94.

61. Chen SZ, Li J, Li XY, Xu LS. Effects of vacuum-assisted closure on wound microcirculation: an experimental study. Asian J Surg 2005;28:211-7.

62. Saxena V, Hwang CW, Huang S, Eichbaum Q, Ingber D, Orgill DP. Vacuum-assisted closure: microdeformations of wounds and cell proliferation. Plast Reconstr Surg 2004; 114:1086-96.

63. Thawer HA, Houghton PE. Effects of ultrasound delivered through a mist of saline to wounds in mice with diabetes mellitus. J Wound Care 2004;13:171-6.

64. Hurwitz H, Fehrenbacher L, Novotny W, et al. Bevacizumab plus irinotecan, fluorouracil, and leucovorin for metastatic colorectal cancer. N Engl J Med 2004;350:2335-42.

65. Hurwitz H. Integrating the anti-VEGF-A humanized monoclonal antibody bevacizumab with chemotherapy in advanced colorectal cancer. Clin Colorectal Cancer 2004;4(Suppl 2): S62-8.

66. Carmeliet $P$, Storkebaum E. Vascular and neuronal effects of VEGF in the nervous system: implications for neurological disorders. Semin Cell Dev Biol 2002;13:39-53.

67. Taguchi A, Soma T, Tanaka H, et al. Administration of CD34+ cells after stroke enhances neurogenesis via angiogenesis in a mouse model. J Clin Invest 2004; 114:330-8.

68. Sondell M, Lundborg G, Kanje M. Vascular endothelial growth factor has neurotrophic activity and stimulates axonal outgrowth, enhancing cell survival and Schwann cell proliferation in the peripheral nervous system. J Neurosci 1999;19:5731-40.

69. Oosthuyse B, Moons L, Storkebaum E, et al. Deletion of the hypoxia-response element in the vascular endothelial growth factor promoter causes motor neuron degeneration. Nat Genet 2001;28:131-8.

70. Islamov RR, Chintalgattu V, Pak ES, Katwa LC, Murashov AK. Induction of VEGF and its FIt-1 receptor after sciatic nerve crush injury. NeuroReport 2004;15:2117-21.

71. Kusano KF, Allendoerfer KL, Munger W, et al. Sonic hedgehog induces arteriogenesis in diabetic vasa nervorum and restores function in diabetic neuropathy. Arterioscler Thromb Vasc Biol 2004;24:2102-7.

72. li M, Nishimura H, Kusano KF, et al. Neuronal nitric oxide synthase mediates statininduced restoration of vasa nervorum and reversal of diabetic neuropathy. Circulation 2005;112:93-102

73. Schratzberger $P$, Walter $\mathrm{DH}$, Rittig $\mathrm{K}$, et al. Reversal of experimental diabetic neuropathy by VEGF gene transfer. J Clin Invest 2001;107:1083-92.

74. Kirchmair R, Walter DH, li M, et al. Antiangiogenesis mediates cisplatin-induced peripheral neuropathy: attenuation or reversal by local vascular endothelial growth factor gene therapy without augmenting tumor growth. Circulation 2005;111:2662-70.

75. Hsieh PS, Bochinski DJ, Lin GT, Nunes L, Lin CS, Lue TF. The effect of vascular endothelial growth factor and brain-derived neurotrophic factor on cavernosal nerve regeneration in a nerve-crush rat model. BJU Int 2003;92:470-5.

76. Generini S, Tuveri MA, Matucci Cerinic M, Mastinu F, Manni L, Aloe L. Topical application of nerve growth factor in human diabetic foot ulcers. A study of three cases. Exp Clin Endocrinol Diabetes 2004;112:542-4.
CONTINUING MEDICAL EDUCATION INFORMATION FOR PHYSICIANS

Wolters Kluwer Health is accredited by the Accreditation Council for Continuing Medical Education to provide continuing medical education for physicians.

Wolters Kluwer Health designates this educational activity for a maximum of 1 category 1 credit toward the AMA Physician's Recognition Award. Each physician should claim only those credits that he/she spent in the activity.

\section{PROVIDER ACCREDITATION INFORMATION FOR NURSES}

This Continuing Nursing Education (CNE) activity for 3.0 contact hours is provided by Lippincott Williams \& Wilkins (LWW), which is accredited as a provider of continuing education in nursing by the American Nurses Credentialing Center's Commission on Accreditation and by the American Association of Critical-Care Nurses (AACN 00012278, CERP Category A). This activity is also provider approved by the California Board of Registered Nursing, Provider Number CEP 00012278 for 3.0 contact hours. LWW is also an approved provider of CNE in Alabama, Florida, and lowa and holds the following provider numbers: AL \#ABNP0114, FL \#FBN2454, IA \#75. All of its home study activities are classified for Texas nursing continuing education requirements as Type 1

Your certificate is valid in all states. This means that your certificate of earned contact hours is valid no matter where you live.

\section{CONTINUING EDUCATION INSTRUCTIONS}

- Read the article beginning on page 491

- Take the test, recording your answers in the test answers section (Section B) of the CE enrollment form. Each question has only one correct answer.
- Complete registration information (Section A) and course evaluation (Section C).

- Mail completed test with registration fee to: Lippincott Williams \& Wilkins, CE Group, 333 7th Avenue, 19th Floor, New York, NY 10001.

- Within 3 to 4 weeks after your CE enrollment form is received, you will be notified of your test results.

- If you pass, you will receive a certificate of earned contact hours and an answer key. Nurses who fail have the option of taking the test again at no additional cost. Only the first entry sent by physicians will be accepted for credit.

- A passing score for this test is 11 correct answers.

- Nurses: Need CE STAT? Visit http://www.nursingcenter.com for immediate results, other CE activities, and your personalized CE planner tool. No Internet access? Call 1-800-933-6525 for other rush service options.

- Questions? Contact Lippincott Williams \& Wilkins: 646-674-6617 or 646674-6621.

Registration Deadline: December 31, 2007 (nurses); December 31, 2006 (physicians)

\section{PAYMENT AND DISCOUNTS:}

- The registration fee for this test is $\$ 19.95$ for nurses; $\$ 20$ for physicians.

- Nurses: If you take two or more tests in any nursing journal published by LWW and send in your CE enrollment forms together, you may deduct $\$ 0.75$ from the price of each test. We offer special discounts for as few as six tests and institutional bulk discounts for multiple tests. Call 1-800933-6525, for more information. 